\title{
Ciclismo: deporte de estrategia (arbitral) en casos de dopaje
}

\author{
Juan Francisco González
}

\section{Sumario}

1. Introducción. 2. El Manejo del Dopaje en los Deportes Profesionales 2.1 Historia 2.2 El Código Antidopaje 3. El Tribunal de Arbitraje Deportivo 3.1 Historia del TAS 3.2 Procedimientos arbitrales ante el TAS 4. Casos Relevantes 4.1 Floyd Landis: ${ }^{1}$ la estrategia de echar la culpa al laboratorio que analizó las muestras 4.2 Alejandro Valverde: ${ }^{2}$ la estrategia de buscar un foro más amigable 4.3 Alberto Contador: ${ }^{3}$ la estrategia del solomillo dopado 4.4 Jan Ullrich: la estrategia procesalista 4.5 Lance Armstrong: ${ }^{4} \mathrm{el}$ cambio radical de estrategia 5. Conclusiones.

\section{INTRODUCCIÓN}

El ciclismo de ruta a nivel profesional es un deporte altamente exigente. Los deportistas requieren largas sesiones de entrenamiento, una alimentación especializada, participar en eventos oficiales durante la gran mayoría del año y una desarrollada capacidad personal para trabajar en equipo. ${ }^{5}$

I. TAS 2007/A/1294 Floyd Landis c. USADA (laudo de 30 de junio de 2008).

2. TAS 2007/A/1396\& 1402 WADA y UCI c. Alcjandro Valverde \& RFEC (laudo de 31 de mayo de 2010).

3. CAS 201L/A/2384 UCl v, Alberto Contador Velasco \& RFEC; CAS 2011/A/2386 WADA v, Alberto Contador Velasco \& RFEC (laudo de 6 de febrero de 2012).

4. TAS 2010/A/2083 UCl c. Jan Ulirich \& Swiss Olympic (laudo de 9 de febrero de 2012).

5. Rick Scott. The Life of a Pro Cyclist, hutp://www.angentouro/california.com/Peloton/TNT-comer/life. of-a-pro.html 
Hay varios tipos de carreras en cuanto a distancia, duración e intensidad. En la carrera de un solo día más famosa del mundo, la Paris-Roubaix, también conocida como el "Infierno del Norte", los ciclistas recorren 257.5 kilómetros en un tiempo aproximado de 6 horas. Durante la edición 2012 de la Paris-Roubaix, de los 248 corredores que tomaron la partida, solamente 86 corredores llegaron a la meta. ${ }^{6}$

Sin lugar a duda la carrera ciclística más famosa del mundo es el Tour de Francia. Durante la edición 2012, los ciclistas recorrieron un total de 3497 kilómetros durante 23 etapas; el ganador de esa edición, el británico Bradley Wiggins, tardó 87 horas, 24 minutos y 47 segundos en llegar a la meta.

Existen 28 carreras oficiales en el año entre enero y octubre, eso sin contar con las competencias no oficiales o los juegos olímpicos. ${ }^{8}$ Ningún corredor profesional está en capacidad de competir en todas. Las carreras se corren por equipos y en cada uno existe un líder que recorre todo el trayecto protegido por sus gregarios y velocistas con el fin de maximizar sus posibilidades de llegar al final con una ventaja física y mental por sobre los miembros de los otros equipos. Dependiendo de la estrategia, existen equipos que recorren el trayecto colocados al final del pelotón para que sean otros los equipos que luchen contra el efecto del viento mientras que otros equipos prefieren ir adelante del pelotón para controlar el ritmo de carrera y evitar caídas por falta de visibilidad.

La estrategia es la clave del deporte y no existe un solo corredor que pueda confiar en su sola capacidad física para ganar una competencia sin tener la estrategia adecuada. La ambición de ganar las competencias, contratos publicitarios, fama mundial y dinero, entre otras razones, lleva a los atletas a adoptar estrategias a veces reñidas con la ética $y$, en algunas ocasiones, a optar por

\footnotetext{
6. Página oficial de la carrera Paris-Roubaix:

http //www.letour.fr/2012/PRX/LIVE/us/100/classement/index.html

7. Página oficial del Tour de Francia: www.letour.fr

8. Página oficial de la Unión Internacional de Ciclistas (UCI); www,uci,ch
} 
tácticas opuestas a las reglas del deporte. En este artículo, se analizan dos tipos distintos de estrategias muy cuestionables y que son utilizadas con frecuencia en el ciclismo profesional: 1) el uso de sustancias y métodos prohibidos para mejorar el rendimiento deportivo (dopaje), y 2) el uso de estrategias legales creativas y cuestionables para impedir la imposición de sanciones cuando los ciclistas son acusados de dopaje.

Mientras el dopaje sirve para lograr resultados deportivos, las estrategias legales empleadas por los atletas sirven para preservar resultados en un elaborado sistema alternativo de administración de justicia (arbitraje) que existe a nivel mundial para juzgar casos de indisciplina entre los que está el uso de sustancias prohibidas para mejorar el rendimiento deportivo.

Para hacer más práctica esta explicación sobre dopaje y arbitraje deportivo, en este artículo se mencionan algunos casos conocidos de dopaje en el ciclismo profesional y la estrategia legal usada por cada ciclista para defenderse en los arbitrajes. Es difícil argumentar que el ciclismo no sea uno de los deportes profesionales con mayores problemas respecto a uso de sustancias prohibidas pero tampoco se debe dejar de observar que el dopaje es un problema de todos los deportes, más aún, cuando hay importantes intereses económicos detrás.

\section{El Manejo del Dopaje en los Deportes Profe- SIONALES}

\subsection{Historia}

El uso de sustancias para mejorar el rendimiento físico y mental no es nuevo. La palabra "dopaje" viene de la palabra holandesa "dop" que es una bebida hecha de cáscara de uva que tomaban los guerreros de la tribu Zulú en Sudáfrica para mejorar su rendimiento en batalla. El término tomó un sentido más con- 
temporáneo durante el siglo 20 cuando se lo utilizó para hacer referencia al uso de drogas para mejorar el rendimiento de los caballos de carreras. ${ }^{9}$

Es imposible saber con certeza cuándo fue la primera vez que un deportista profesional mejoró su rendimiento de forma artificial; en el caso del ciclismo de manera particular, pero también en otros deportes de resistencia, se conoce que durante el siglo 19 los atletas utilizaron estricnina, cafeína, cocaína y alcohol para mejorar su rendimiento en competencia.

En 1928, la Asociación Internacional de Federaciones de Atletismo (IAAF, por sus siglas en inglés) prohibió a los atletas el uso de algunas sustancias; sin embargo no se dieron resultados positivos porque no se les practicaba exámenes a los deportistas. Durante los Juegos Olímpicos de Roma en 1960 murió el ciclista Knud Enamark durante la competencia; la autopsia reveló la presencia de anfetaminas. Solamente en 1966 la Unión Ciclista Internacional (UCI) y la Federación Internacional de Futbol Asociación (FIFA) empezaron a practicar exámenes de sangre a sus atletas. Aun así, en 1967 otro ciclista, Tom Simpson, murió mientras competía en el Tour de Francia. ${ }^{10}$

El uso de distintas sustancias y métodos de dopaje continuaron desarrollándose con el avance de la ciencia, lo cual hasta esta fecha es uno de los mayores problemas: el uso de sustancias y métodos dopantes siempre está por delante de su detección y control. ${ }^{11}$

Uno de los momentos más delicados respecto al dopaje en el ciclismo fue el Tour de Francia de 1998, bautizado como el "Tour de la Vergüenza". Una redada de la policía francesa a los hoteles de los ciclistas sirvió para encontrar que varios equipos estaban en posesión de sustancias prohibidas y controladas

9. Pagina oficial de la Agencia Mundial Antidopaje (AMA): hltp://www.wada-ama org/en/AboutWADA History A-Bricf-History-of-Anti-Doping/

10. AMA: htip//www wada-ama org/en/About-WVADA/History/A-Brief-History-of-Anti-Dopıng

11. Ibidem. 
como eritropoyetina (EPO), hormonas de crecimiento, testosterona, y anfetaminas. Luego de tensas negociaciones entre la policía, la organización del Tour y los equipos, solamente 98 corredores terminaron la competencia. ${ }^{12}$

El incidente del Tour de Francia del 98 dio lugar a que el Comité Olímpico Internacional convocara a la primera Conferencia Mundial sobre Dopaje en Lausana, Suiza en febrero de 1999. Como resultado de la Conferencia, el 10 de noviembre de 1999, se creó la Agencia Mundial Antidopaje (AMA o WADA por sus siglas en inglés). ${ }^{13}$

Actualmente la AMA opera conjuntamente con atletas, gobiernos, federaciones deportivas internacionales y nacionales, organizaciones antidopaje, laboratorios, entre otros. Mientras que la función de las organizaciones antidopaje es perseguir la violación de las reglas antidopaje, el papel de las federaciones internacionales y nacionales, entre otras actividades, es establecer paneles de primera instancia para el juzgamiento de potenciales violaciones.

\subsection{El Código Antidopaje}

La Agencia Mundial Antidopaje redactó y puso en vigencia el Código Mundial Antidopaje (también conocido como el "Código AMA" o "Código Antidopaje") el $1^{\circ}$ de enero de 2004. En el año 2006 el Código fue revisado y reformado; esas reformas entraron en vigencia en el año 2009 para darle más fuerza y uniformidad en los procedimientos, de tal manera que cumpla mejor con los objetivos de la AMA: 1) proteger el derecho fundamental de los atletas a participar en deportes libres de dopaje, de tal manera que se proteja la salud, la justicia y la igualdad de los atletas; y 2) asegurar programas antidopaje armonizados, coordinados y

12. CBS News: http://www.cbsnews.com/2316-100 162-3093937-11.html, y Samuel Abt, Angered by. Police Raids, Riders Stage Slowdown: Totur de France Crawis Toward the Finish Line (The New York Times), http://www.nytimes.com/1998/07/30/news/30iht-bike.t 12.html

13. AMA: http://www.wada-ama.org/en/About-WADA/History/A-Bricf-History-of-Anti-Doping/ 
efectivos a nivel internacional y nacional en cuanto a detección, disuasión y prevención. ${ }^{14}$

Actualmente el Código rige para las organizaciones deportivas internacionales más importantes: el Comité Olímpico Internacional, las federaciones internacionales de 33 deportes entre los que está la FIFA y los comités olímpicos de 204 países del mundo. ${ }^{15}$ En consecuencia, los deportistas que participan en los eventos organizados o controlados por esas federaciones o los comités internacionales, también están regidos por el Código Antidopaje. El Comité de Administración de la UCI incorporó el Código Antidopaje a sus propias reglas el 13 de agosto de 2004.

Son pocos los deportes para los cuales el Código Antidopaje no rige (por ejemplo, béisbol y fútbol americano) pero a cada organización deportiva que está fuera de la AMA le rige algún tipo de sistema de juzgamiento de este tipo de conductas.

A continuación se explican brevemente algunas disposiciones del Código AMA que han tenido especial relevancia en los casos de dopaje de ciclistas profesionales:

- Violaciones a las reglas antidopaje: El artículo 2 del Código AMA determina los actos que constituyen violaciones a las reglas antidopaje en términos muy amplios. Estas violaciones incluyen el uso, posesión o intento de uso de sustancias prohibidas y controladas; el uso o intento de uso de métodos prohibidos; el rehusarse a la práctica o entregar muestras; la violación de reglas de disponibilidad para la práctica de muestras; la alteración de resultados de las muestras y el tráfico de sustancias y métodos prohibidos, entre otras actividades también incluidas como violaciones a reglas antidopaje. ${ }^{16}$

14. AMA http:/www, wada-ama org/en/World-Anti-Doping-Program/Sports-and-Anti-Doping-Organizations/The-Code/

15. AMA: http://www wada-ama org/en/World-Anti-Doping-Program/Sports-and-Anti-Doping-Organizations/The-Code/Code-Acceptance/Olympic-Movement

16. Articulo 2 del Código Antidopaje. 
- Obligación de los deportistas: Es obligación de todo atleta asegurarse que ninguna sustancia prohibida, método prohibido, metabolitos o marcadores aparezcan en sus muestras. Adicionalmente, y aquí un tema muy relevante en los procesos arbitrales que se mencionarán más adelante, no es necesario que el atleta tenga la intención, incurra en culpa o negligencia o que tenga conocimiento de su uso de sustancias o métodos prohibidos para que éste incurra en una violación a reglas antidopaje. ${ }^{17} \mathrm{La}$ sola presencia de una sustancia prohibida, metabolitos o marcadores, o la detección de un método prohibido es "prueba suficiente de una violación antidopaje". ${ }^{18}$

- Criterios ("estándares") para la determinación de violaciones y carga de la prueba: Cada organización antidopaje tiene la carga de la prueba para demostrar que se ha producido una violación a una regla antidopaje. Para esto, un panel de cada organización debe analizar cada caso para llegar a la "cómoda satisfacción" ${ }^{19}$ de que se ha producido una violación a una regla antidopaje. El estándar de cómoda satisfacción se replica en las Reglas de Resolución de disputas de la UCI y por tanto también aplica (o debería aplicar) a las federaciones nacionales de ciclismo que juzgan a sus deportistas en primera instancia. Tanto en el Código Antidopaje como en las reglas UCI se establece que cuando la carga de la prueba se transfiere al atleta (u otro acusado), el criterio para la determinación de responsabilidad es el de "balance de probabilidad". ${ }^{20}$ La carga de la prueba se transfiere al atleta cuando éste alega que el laboratorio ha incumplido con los estándares internacionales de toma y manejo de muestras ${ }^{21}$ o cuando alega que la sustancia fue ingerida sin intención de obtener un mejor rendimiento deportivo ${ }^{22}$.

17. Articulo 2.1.1 del Código Antidopaje.

18. Articulo 2.1.2 del Código Antidopaje.

19. Según el articulo 3.1 del Código, cl criterio de cómoda satisfacción es mayor al de "mero balanee de probabilidad" de que se haya producido una violación pero menor al criterio de "más allá de la duda razonable".

20. Articulo 3.1 del Código Antidopaje y Articulo 22 de las Reglas Antidopaje de la UCI. 
- Lista de sustancias y métodos prohibidos: Todas las sustancias y métodos que constituyen violaciones a reglas antidopajes aparecen en una lista. El Código habilita a la AMA para actualizar la lista de sustancias y métodos que están prohibidos en general o para un deporte en particular, durante y fuera de competición. ${ }^{23} \mathrm{La}$ lista de sustancias y métodos prohibidos se puede encontrar en la página web de la $\mathrm{AMA}^{24}$ y en la página web de la UCI para el caso específico del ciclismo. ${ }^{25}$

- Utilización restringida de sustancias prohibidas: Bajo ciertas circunstancias y requisitos se permite el uso de sustancias prohibidas con fines terapéuticos. ${ }^{26}$

- Derecho a tomar muestras: Salvo limitaciones durante competencias, las organizaciones antidopaje nacionales tienen la capacidad para realizar exámenes a los atletas que sean nacionales, residentes, tengan carnet o que sean miembros de organizaciones deportivas de ese país. Cada federación internacional (como la UCI) tiene la capacidad para realizar exámenes a los atletas afiliados a las federaciones nacionales que forman parte de esa federación internacional o a los atletas que participan en los eventos organizados por éstas (por ejemplo, la Federación Ecuatoriana de Ciclismo). ${ }^{27}$ Las muestras pueden ser tomadas en cualquier momento, aun cuando los atletas no estén en competencia.

- Derecho a audiencias justas: El Código establece el derecho a que el deportista que haya dado positivo tenga audiencias justas, lo que incluye el derecho a audiencias oportunas, paneles justos e imparciales, derecho a contar

21. Articulo 3.2.1 del Código Antidopaje.

22. Artículo $10.4 \mathrm{del}$ Código Antidopaje.

23. Articulo 4.2.1 del Código Antidopajc.

24. AMA: http//list.wada-ama.org/es/

25. UCl: hitp://www.uci.ch/lemplates/UCl/UCl5/layout.asp?Menuld MjlONQ\&Langld=1

26. Articulo $4.4 \mathrm{del}$ Código Antidopaje.

27. Artículo 5.1 del Código Antidopaje. 
con un abogado, derecho a ser informado justa y oportunamente sobre la violación de la que se le acusa, derecho a réplica, derecho a presentar pruebas, derecho a un intérprete y el derecho a decisiones oportunas, escritas y razonadas. $^{28}$

- Sanciones: Las sanciones por violaciones a reglas antidopaje se resumen en:

" Descalificación: El atleta que de positivo durante una competencia, independientemente de si existe culpa, es automáticamente descalificado y pierde todas las medallas, puntos y premios que haya recibido. ${ }^{29}$ Adicionalmente, como regla general, el atleta que incurra en una violación antidopaje durante un evento deportivo será sancionado con descalificación de todas las competencias realizadas durante ese evento ${ }^{30} ; y$,

"Inhabilitación: Los atletas y otras personas que incurren en violaciones a reglas antidopaje también quedan inhabilitados de participar en eventos oficiales durante un tiempo determinado. Dependiendo del tipo de violación que se haya cometido de acuerdo al artículo 2 del Código, el periodo de inhabilitación puede variar. La sanción común por primera violación es de 2 años ${ }^{31}$ para la mayoría de tipos de violaciones y de 4 años para tráfico de sustancias prohibidas y para la administración o intento de administración de sustancias prohibidas en competencia. ${ }^{32} \mathrm{El}$ periodo de inhabilitación puede variar en razón de agravantes y atenuantes, número de violaciones cometidas y/o reincidencia. Por regla gene-

28. Articulo 8 del Código Antidopajc.

29. Artículo 9 del Código Antidopaje.

30. Mientras una "competencia" en el sentido del Art. 9 se refiere a una ùnica competencia, "evento" en el sentido del Art. 10 se refiere a un grupo de compeiencias organizadas dentro de un periodo (por cjemplo, un cvento Mundial o las Olimpiadas).

31. Articulos 10.2 y 10.3.1 del Código Antidopaje.

32. Articulo 10.3.2 del Código Antidopaje. 
ral, la tercera violación antidopaje resulta en la inhabilitación de por vida. ${ }^{33}$

- Eliminación y reducción de sanciones: El Código prevé la posibilidad de eliminación o reducción de las sanciones en casos de uso de sustancias específicas en circunstancias específicas $^{34}$ o por la existencia de circunstancias excepcionales ${ }^{35}$. Estas circunstancias de eliminación o reducción de las sanciones son particularmente importantes en los arbitrajes porque una vez que las muestras arrojan resultados positivos, las estrategias más utilizadas apuntan a buscar circunstancias que sirvan para eliminar o, por lo menos, reducir las sanciones.

- Apelación de las sanciones impuestas: Todas las decisiones emitidas por federaciones nacionales o internacionales son susceptibles de apelación. ${ }^{36}$ Cuando esa decisión tiene relación con eventos o atletas internacionales, la apelación debe ser planteada de manera exclusiva, ante el Tribunal de Arbitraje Deportivo (en adelante "TAS" por sus siglas en francés, "Tribunal Arbitral du Sport"). La AMA tiene el derecho para apelar de todas las decisiones tomadas por las federaciones en primera instancia respecto a violaciones a reglas antidopaje. La UCI, al haber incorporado el Código Antidopaje a sus reglas, también puede apelar de las decisiones de primera instancia. ${ }^{37}$ 


\section{EL TRIBUNAL DE ARBITRAJE DEPORTIVO}

\subsection{Historia del TAS}

El Tribunal de Arbitraje Deportivo ${ }^{38}$ es el más importante organismo para la resolución de disputas relacionadas con actividades deportivas profesionales a nivel internacional. El TAS fue creado en 1983 como una rama del Comité Olímpico Internacional para brindar un método "flexible, rápido y económico" para resolver disputas deportivas. ${ }^{39}$

De esa fecha hasta hoy, el TAS ha tenido algunos cambios importantes, pero para efectos de desarrollar el tema que aquí se trata, es necesario mencionar dos hechos relevantes. En 1991 el TAS promulgó una Guía para el arbitraje, en la que incluyó varias cláusulas arbitrales modelo. Entre estas cláusulas, se insertó una para que fuese implementada en los estatutos y reglamentos de las federaciones deportivas y clubes. ${ }^{40}$ Esta cláusula abrió la puerta para que las resoluciones dictadas por las federaciones deportivas fueran revisadas en apelación por un tribunal arbitral TAS (en adelante "paneles"). Posteriormente, en noviembre de 1994 se emitió el Código de Arbitraje Deportivo que creó tres procedimientos arbitrales distintos que son los que se usan actualmente: a) el arbitraje ordinario, b) el arbitraje de apelaciones, y c) el arbitraje ad-hoc. ${ }^{41}$

El TAS tiene como sede Lausana, Suiza. En consecuencia, los procesos arbitrales están sujetos a la Ley Suiza de Derecho Internacional Privado que establece que los laudos de los paneles TAS son definitivos y además establece las causas particulares por las que los laudos pueden ser anulables por la Corte Suprema de Suiza. ${ }^{42}$

38. Página oficial del Tribunal de Arbitraje Dep̣ortivo (TAS) : www.tas-cas.org

39. TAS: http://www tas-cas org/history

40. TAS: hut: / $/$ www tas-cas org/en/arbitrage asp /4-3-285-1021-4-1-1/5-0-1021-3-0-0/

41. TAS: http://www tas-cas org/en/infogenerales.asp/4-3-236-1011-4-1-1/5-0-1011-3-0-1)/

42. William McAuliffe, Antonio Rigozzi y Lévy Kaufmann-Kohler. Glohal Arbitration Restew; Sports Arbitration (The European \& Middle Eastern Arbitration Review 2012). 


\subsection{Procedimientos arbitrales ante el TAS}

En esencia, el primer tipo de procedimiento, conocido como procedimiento ordinario, sirve para resolver disputas contractuales (usualmente comerciales) siempre dentro del ámbito deportivo profesional y el tercer tipo de procedimiento el arbitraje ad-hoc sirve para resolver asuntos disciplinarios en determinados eventos deportivos que requieren de una resolución inmediata (por ejemplo, durante los Juegos Olímpicos). En este artículo se desarrolla el segundo tipo de arbitraje, conocido como procedimiento de apelaciones que convierte al TAS en una entidad de apelación de decisiones disciplinarias entre las que están los procesos que llevan adelante los órganos antidopaje por violaciones a las reglas aplicables a la materia.

El procedimiento de apelaciones, que representa aproximadamente el $90 \%$ de la carga de casos del TAS ${ }^{43}$, brinda un foro independiente a las organizaciones antidopaje (como la UCI) y a los atletas investigados cuando existe insatisfacción de cualquiera de las partes involucradas con la decisión adoptada en primera instancia. Los paneles de apelación, conformados por 1 o 3 árbitros, tienen amplias atribuciones para revisar los hechos y las normas aplicables para así dictar una decisión nueva que se sobrepone a la adoptada en la instancia anterior. ${ }^{4+}$

De manera particular, las decisiones de órganos antidopaje contra o a favor de ciclistas que participan en eventos oficiales de la UCI son únicamente apelables ante el TAS. ${ }^{45}$

Las apelaciones pueden ser presentadas por el deportista o por la persona acusada de violaciones antidopaje, por las federaciones nacionales o internacionales y también por la Agencia Mundial Antidopaje. ${ }^{+6}$ Como se verá a continuación, es usual que

43. Jbidem.

44. Articulo R57 del Código Antidopaje.

45. Articulo 330 de las Reglas Antidopaje de la UCI.

46. William McAulifle, Antonio Rigozzi y Lévy Kaufmann-Kohler Glohal Arbitration Revicue Sports Arbitratiom (The European \& Middle Eastern Arbitration Review 2012). 
en un mismo caso existan múltiples apelantes y/o múltiples partes que deben responder en apelación.

\section{Casos relevantes}

Son muchos los ciclistas profesionales involucrados en casos de dopaje que han llegado al TAS. A continuación se presentan cuatro casos arbitrales que involucraron a ciclistas que pueden ser reconocibles por personas no relacionadas con el deporte. Aquí no se abarcan todos los puntos discutidos en cada uno de los casos, de hecho, quedan fuera de este análisis muchos temas muy importantes pero que, por alejarse del tema central de este documento, deberán ser revisados en otro momento. El enfoque de este artículo es revisar las varias estrategias legales usadas por estos ciclistas (y otras partes involucradas) para intentar eliminar o reducir sus sanciones por dopaje.

Finalmente se presenta el caso de otro ciclista, éste sí, reconocible aun por quienes nunca se han subido a una bicicleta, que aun cuando no llegó a un arbitraje, es sumamente importante revisarlo en este artículo porque justamente, la estrategia de este ciclista fue no llegar al arbitraje para evitar ciertas consecuencias.

\subsection{Floyd Landis: ${ }^{47}$ la estrategia de echar la culpa al labora- torio que analizó las muestras}

El ganador del Tour de Francia del 2006 fue el estadounidense Floyd Landis. Al final de la etapa 17 del Tour, a Landis se le solicitó una muestra que luego de los exámenes practicados, de acuerdo a la UCI, resultó positivo por testosterona exógena. ${ }^{48}$

Landis pidió a un Panel de revisión de la United States Anti-

47. TAS 2007/A/1294 Floyd Landis c. USADA (laudo de 30 de junio de 2008).

48. La testosterona exógena es una sustancia que consta en la Lista de Prohibidos de 2006 como un tipo de esteroide anabólico. 
Doping Agency (USADA), la organización antidopaje de los Estados Unidos, que desechara el caso alegando que los exámenes realizados a las muestras no cumplían con los estándares aceptados y que se había producido un rompimiento en la cadena de custodia de las muestras, lo que las invalidaba. Como el panel rechazó el pedido del ciclista, inició la primera instancia ante un panel arbitral que, de acuerdo a las reglas de la USADA, lo conforma un tribunal de la American Arbitration Association (AAA).

El panel AAA resolvió, en septiembre de 2007, y por mayoría, que las muestras habían sido tomadas de acuerdo a las regulaciones de la UCI y que, por tanto, correspondía sancionar a Floyd Landis con la descalificación de su resultado del Tour de France 2007 y la inhabilitación de competir por 2 años.

En octubre del 2007, Floyd Landis apeló de la decisión del panel AAA ante el TAS alegando nuevamente que la toma de muestras había sido realizada sin observar los estándares internacionales para laboratorios acreditados y que además se había violado la cadena de custodia de las muestras.

Como el ciclista alegó que las muestras no se apegaban a los estándares internacionales, la carga de la prueba se transfirió del panel de la AAA a Landis quien debía demostrar que, haciendo un balance de probabilidades, las muestras habían sido mal practicadas y mal manejadas. En el caso de que el ciclista hubiese logrado demostrar esto, la carga de la prueba hubiese retornado a la AAA quien habría tenido que dar la cómoda satisfacción al Panel TAS, que esa mala práctica y manejo de muestras no habrían sido la causa del resultado positivo de los exámenes.

El 30 de junio del 2008 el panel CAS resolvió en contra de Floyd Landis. Ese panel, conformado por tres juristas muy bien conocidos y reputados en el mundo del arbitraje internacional (David Williams, David Rivkin y Jan Paulsson), no encontró en los alegatos de Landis, argumentos suficientes para determinar con "cómoda satisfacción" que los métodos empleados para el es- 
tudio de las muestras o que la manera en que fueron manejadas las muestras ponía en duda la presencia de testosterona exógena en la orina del atleta ni tampoco que estuviera en duda que las muestras tomadas fueran suyas.

\subsection{Alejandro Valverde: ${ }^{49}$ la estrategia de buscar un foro más amigable}

Se conoce como "Operación Puerto" a uno de los operativos policiales/judiciales más importantes a nivel mundial en temas de dopaje. La Operación Puerto inició en España luego de que la Guardia Civil recibiera información sobre una red de suministro de sustancias dopantes a deportistas profesionales. El 23 de mayo de 2006 la Guardia Civil detuvo a cinco personas en Madrid y Zaragoza y registró varias propiedades en las que encontró 200 bolsas congeladas de plasma y glóbulos rojos, documentos relacionados con dopaje, EPO, anabolizantes, hormonas de crecimiento y esteroides. ${ }^{50}$ Todas las bolsas congeladas contaban con códigos que, relacionándolos con otras piezas probatorias, sirvieron para determinar los nombres de los atletas profesionales que se estaban beneficiando de esa red de dopaje.

La bolsa de sangre No. 18, de acuerdo a las investigaciones de la Operación Puerto, pertenecía al ciclista español Alejandro Valverde. El 29 de agosto del 2007 la UCI solicitó a la Real Federación Española de Ciclismo (RFEC) que inicie acciones disciplinarias en contra de Valverde. En septiembre de ese año, el Comité Nacional de Competición y Disciplina Deportiva (CNCDD) y el Presidente de la RFEC se negaron a abrir el proceso disciplinario solicitado. Las razones por las que la CNCDD y la RFEC se negaron a iniciar procedimientos disciplinarios en contra del ciclista fueron 1) que los documentos con los que contaban no daban indicaciones de que Valverde estuviera involucrado en asuntos de dopaje; 2) que la investigación de la Guardia Civil no identificaba

49. TAS 2007/A/1396\& 1402 WADA y UCI c. Alejandro Valverde \& RFEC (laudo de 31 de mayo de 2010).

50. La 'operación Puerto' paso a paso (EL MUNDO).

http://www.elmundo cs/elmundodeporte/2006/06/27/ciclismo/1151402208. html 
a Valverde como un sospechoso; 3) que Valverde había demostrado ser inocente; y 4) porque una corte española (No. 31) había prohibido que se usen las pruebas obtenidas en los procedimientos penales relacionados con la Operación Puerto. Paradójicamente, el 30 de enero de 2009, las cortes españolas archivaron la investigación penal en contra de todos los implicados en el caso.

Sin embargo en Italia, tanto las cortes ordinarias como los organismos antidopaje iniciaron y continuaron investigaciones por el presunto cometimiento de delitos y violaciones a reglas antidopaje en ese país. El 11 de mayo de 2009 el Tribunale Nazionale Antidoping (TNA) encontró que Alejandro Valverde había violado el Art. 2.2 de Código AMA que se refiere al uso o intento de uso de sustancias y métodos prohibidos y, por tanto, se prohibió la participación de Valverde en eventos ciclísticos en Italia. Valverde apeló de esta decisión ante un TAS y el 16 de marzo del 2010 el Panel TAS ratificó la decisión del TNA.

Como la RFEC se negó a iniciar un proceso disciplinario en contra del ciclista, AMA y UCI, conjuntamente, plantearon una apelación ante un panel TAS. En esencia, las apelantes alegaron que Valverde había cometido violaciones a reglas antidopaje al usar y tratar de usar sustancias y/o métodos prohibidos. Valverde respondió que: 1) el Panel TAS no tenía competencia para resolver sobre su inocencia o culpabilidad y que cualquier decisión del panel debía limitarse a ordenar que la RFEC inicie un proceso disciplinario de primera instancia. Adicionalmente el ciclista alegó que el Panel TAS no tenía la capacidad para utilizar las pruebas obtenidas en la Operación Puerto para juzgarlo.

Uno de los temas centrales de este caso es si los paneles TAS, como tribunal de apelación de decisiones disciplinarias de primera instancia, tienen la competencia para resolver que existe una violación a reglas antidopaje aun cuando en la primera instancia, el organismo antidopaje haya decidido no iniciar un procedimiento disciplinario.

El Panel TAS consideró que la decisión de la RFEC de no 
abrir el expediente disciplinario en contra de Alejandro Valverde en efecto era una decisión apelable ante el TAS porque las Reglas Antidopaje de la UCI vigentes en el $2004^{51}$ le daban la capacidad para recibir en apelación todas las "decisiones" de federaciones nacionales y que las decisiones de la RFEC establecían sin duda una posición legal sustancial respecto a la situación del ciclista.

El segundo tema que resolvió el Panel TAS es respecto a si tenía la capacidad de resolver sobre la inocencia o culpabilidad de Valverde o si debía redirigir el caso a la RFEC para que sea ésta quien juzgue al atleta. El Panel se declaró competente para emitir una nueva decisión sobre la responsabilidad de Valverde sobre la base del artículo R57 del Código TAS, que le otorga a todo panel TAS "completo poder para revisar los hechos y el derecho para ya sea emitir una nueva decisión y reemplazar la decisión apelada o anular la decisión apelada y referir el caso a la instancia previa" ${ }^{\prime 2}$.

Si es que la posición de Valverde hubiera prevalecido, el Panel TAS debía ordenar que la RFEC abra un proceso disciplinario en contra del corredor pero, con buenas probabilidades, la RFEC habría abierto el proceso pero se habría negado a utilizar las pruebas de la Operación Puerto por la orden judicial que ya se mencionó. Es decir que la estrategia de Valverde era redireccionar el caso a un órgano antidopaje que, por convicción o preferencia, no tendría elementos de prueba suficiente para juzgarlo.

Respecto al argumento planteado por Valverde de que se le estaba negando el derecho a la primera instancia, el Panel TAS encontró que el artículo R57 del Código TAS era suficientemente claro respecto al poder para revisar de novo el caso, más aún cuando las decisiones de la RFEC sí se pronunciaron sobre la inocencia o culpabilidad del ciclista.

51 Artículo 280, literal a) de las Reglas Antidopaje de la UCI (2004).

52. Traducción informal. 
Del Artículo R57 del Código CAS y de su desarrollo jurisprudencial queda claro que los paneles TAS tienen toda la capacidad para juzgar de novo si existió una violación a una regla antidopaje y que los atletas que han intentado limitar la capacidad de un panel TAS para resolver sobre el fondo no han tenido resultados favorables.

A pesar de los incidentes procesales planteados por la defensa de Alejandro Valverde, el Panel TAS analizó si el atleta había cometido una violación a reglas antidopaje. En primer lugar, el Panel hizo notar que bajo la ley aplicable de Suiza, que rige a los procesos del TAS, aun si las pruebas recabadas durante la Operación Puerto hubiesen sido tomadas en violación de ciertos derechos humanos, sí tienen validez cuando existe un interés de orden público y que la lucha internacional en contra del dopaje es uno de esos intereses de orden público.

Aceptada la prueba recabada en la Operación Puerto, las apelantes demostraron científicamente que la Bolsa No. 18 contenía EPO y que las pruebas de ADN demostraban que esa misma bolsa contenía sangre de Alejandro Valverde. Consecuentemente el ciclista fue sancionado con una suspensión de dos años.

A manera de comentario, se debe notar que la RFEC nunca disputó esta evidencia científica mientras que el ciclista se limitó a desarrollar una teoría de por qué su sangre estaba en la Bolsa No. 18 y de cómo fue que las muestras no fueron adecuadamente tomadas para efectos de control antidopaje. Bajo riesgo de caer en redundancias, nótese que en este caso, el ciclista en cuestión tampoco negó haberse dopado.

La conclusión en este caso es que la estrategia planteada por el ciclista y por la RFEC de regresar el caso a primera instancia no funcionó. De la lectura de los documentos del caso queda claro que si el Panel TAS habría ordenando que la RFEC juzgue en primera instancia a Valverde, el ciclista habría sido declarado inocente. Pero esta estrategia a la larga también habría fracasado 
porque con toda seguridad la AMA y la UCI habrían apelado de esa eventual decisión del RFEC y que los apelantes habrían tenido más elementos en base a las pruebas brindadas por la Operación Puerto para que un nuevo panel TAS sancione al corredor.

\subsection{Alberto Contador: ${ }^{53}$ la estrategia del solomillo dopado}

En el 2007 Alberto Contador se convirtió en el ciclista español más joven en ganar el Tour de Francia. Luego volvió a ganar el Tour en el 2009 y de nuevo en el 2010 (o eso pensó). Además en el 2008 ganó las otras dos grandes carreras, el Giro de Italia y la Vuelta a España. Sin lugar a dudas es el corredor español más exitoso de los últimos tiempos.

El 21 de julio del 2010, en un día de descanso del Tour de Francia, Contador se realizó un control antidopaje solicitado por la UCI. El resultado de ese control determinó que la muestra del corredor contenía clembuterol que es una sustancia prohibida de acuerdo a la lista de la AMA del año 2010.

Un mes después de que Contador "ganó" el Tour de Francia, fue notificado que su control había dado positivo. Desde el inicio el ciclista justificó el positivo diciendo que se había comido un solomillo de ternera que un amigo le había comprado en el pueblo de Irún, España y que él y otros miembros de su equipo se lo comieron entre el 20 y el 21 de julio durante la competencia. Como parte de la explicación el hambriento ciclista desarrolló una elaborada teoría de cómo fue que solo él dio positivo mientras que sus otros compañeros pasaron todos los controles que se les practicaron durante el Tour. ${ }^{54}$

En primera instancia el ciclista fue completamente absuelto. Esto a pesar de que un informe preliminar de la CNCDD deter-

53. CAS 2011/A/2384 UCI v Alberto Contador Velasco \& RFEC, CAS 2011/A/2386 WADA y, Alberto Contador Velasco \& RFEC (laudo de 6 de febrero de 2012)

54. Tras la pisla de un solomillo de Irin (El Pais).

http://deportes elpais com/deportes/2010/09/30/actualidad/1285831333_850215.htm/ 
minó que "sin culpa o negligencia significativa", Contador había cometido una violación a reglas antidopaje por lo que sugería la imposición de una suspensión de un año. En la decisión de primera instancia la RFEC consideró que luego de hacer un balance justo de los documentos existía una "gran probabilidad"55 de que Alberto Contador, en un ejercicio de "máxima prudencia" habría ingerido clembuterol sin su conocimiento a través de la ingesta del solomillo más famoso del ciclismo mundial. ${ }^{56}$

Sin entrar a analizar el fondo de la decisión de primera instancia, hay que mencionar que esa decisión habría permitido a Contador participar en los Juegos Olímpicos de Londres 2012. Sin embargo, AMA y UCI apelaron de la decisión de la RFEC ante el TAS en marzo del $2011^{57}$ (posteriormente las dos apelaciones fueron consolidadas) lo que a la larga resultó en una descalificación tanto del Tour de Francia como de las Olimpiadas del 2012.

AMA y UCI fundamentaron su apelación en que no estaba en disputa que las muestras de Contador habían dado positivo y que el corredor no había demostrado que la ingesta de la sustancia prohibida se había producido sin su culpa o negligencia para efectos de una absolución o una reducción de la sanción. Adicionalmente las apelantes desarrollaron toda una estrategia sobre la base del criterio de balance de probabilidades para presentar teorías alternativas a la teoría del solomillo dopado que habrían sido más verosímiles. Según las apelantes, era más probable que el ciclista habría ingerido clembuterol a través de: a) transfusiones de plasma que además lograban explicar la presencia de residuos plásticos en las muestras del corredor dado que ciertas bolsas de suero usadas para transfusiones se desprenden esos residuos; o b) suplementos alimenticios. Los apelantes también alegaron que era menos probable la teoría del solomillo porque el uso de clembuterol para engorde de animales en Europa es una actividad penalizada y que no existían bases para pensar que los animales de

55. "Gran probubilitad" no es un criterio que exista en el juzgamiento disciplinario de deportistas para determinar si se cometió o no una violación a reglas de dop̣aje.

56. Pärrafo $28 \mathrm{dcl}$ laudo.

57. Las apelaciones fucron presentadas por separado pero luego fueron consolidadas para que sea un mismo Panel TAS quien resuclva. 
Irún (el pueblo donde se compró el solomillo en cuestión) podrían estar contaminados con clembuterol.

Los argumentos de defensa de Contador se pueden resumir en que era más probable que improbable que la ingesta de clembuterol hubiese sido causada por haber comido solomillo porque dar clembuterol a los animales es una práctica común en España.

Para el Panel TAS, no era posible descartar ni la teoría del solomillo, ni tampoco las teorías de la transfusión de sangre o la de los suplementos alimenticios; de hecho para el Panel la teoría de los suplementos era la que con mayor probabilidad explicaba el clembuterol en las muestras del corredor. Según el Panel, la mera posibilidad de que el solomillo habría podido estar contaminado con clembuterol no era prueba suficiente para exculpar a Contador. Consecuentemente, el Panel TAS encontró que el corredor era culpable de dopaje. La sanción que le correspondió a Contador fue la revocatoria de su título de ganador del Tour de Francia 2012 y la suspensión por dos años.

En este caso, la UCI y la AMA como apelantes de la decisión de primera instancia fueron tremendamente efectivos en valerse del estándar de prueba de "balance de probabilidades" (establecido para la reducción de sanciones) para demostrar que Contador no había superado ese estándar. Ante la alegación del ciclista de que lo más probable era que el solomillo que comió fue el causante de la contaminación, los apelantes plantearon teorías alternativas de cómo Alberto Contador habría consumido clembuterol. Al presentar teorías alternativas, lograron que el Panel TAS llegase a la conclusión de que habían teorías más probables para el dopaje que un extrañamente simple y poco demostrable consumo de carne.

Del caso Contador y también del caso Valverde se puede hacer la crítica a la Real Federación de Ciclismo de España que en primera instancia, o no encontraron razones para sancionar al atleta, o no tuvieron suficientes elementos de juicio para iniciar 
el expediente. Estas decisiones de la RFEC sientan un muy mal precedente respecto a la indulgencia e irregularidad con la que los funcionarios manejan los expedientes disciplinarios de sus atletas. Pero aun más reprochable es la injerencia política del Presidente de España, José Luis Rodríguez Zapatero quien, antes de que RFEC se pronuncie sobre el caso Contador, salió a luz pública a defender al ciclista ${ }^{58} \mathrm{La}$ injerencia política en el deporte es censurable a todo nivel y mucho más cuando la intención es defender a un deportista que, a la postre, se demostró que cometió una irregularidad.

\subsection{Jan Ullrich: ${ }^{59}$ la estrategia procesalista}

En la lista de deportistas implicados en la Operación Puerto apareció el nombre de Jan Ullrich, ganador del Tour de Francia de 1997 y de la medalla de oro de la carrera de ruta de las Olimpiadas de Sídney 2000. En junio de 2006, Ullrich fue suspendido por su equipo y retirado del Tour de Francia que iniciaba pocos días después y en julio de ese mismo año su equipo lo despidió.

En agosto de 2006 la UCI solicitó a la Federación de Ciclismo de Suiza (FCS) la apertura de un proceso disciplinario en contra del ciclista ${ }^{60}$ y él, parecería que para evitar ese proceso, renunció a la membresía de la FCS el 19 de octubre de 2006.

En primera instancia (mayo del 2009), la Cámara Disciplinaria del organismo olímpico de Suiza resolvió, sin entrar a analizar el fondo, que el estatuto olímpico suizo vigente en el 2006, no le permitía iniciar procesos en contra de atletas que habían renunciado a su membresía. Ante esta decisión, la UCI planteó apelación ante el TAS en marzo del 2010 en la que solicitó que se desestime la decisión de la Cámara Disciplinaria y que se declare

58. Zapatero: "No hay razin juridica para sancionar a Contador" (Diario Marca). http:/www.marca.com/2011/02/10/ciclismo/1297370794.html

59. TAS 2010/A/2083 UCI c. Jan Ultrich \& Swiss Olympic (laudo de 9 de febrero de 2012).

60. Jan Ulirich vivia en ese entones en Suiza por lo que estaba afiliado a la Federación de Ciclistmo de Suiza a pesar de ser alemán. 
que Jan Ullrich había cometido violaciones a reglas antidopaje de acuerdo a las reglas de la misma UCI.

Al igual que sucede en arbitrajes no deportivos, el panel TAS resolvió bifurcar el proceso en una etapa de jurisdicción y en otra etapa de fondo. En marzo de 2011, el Panel TAS emitió un laudo parcial en el que se declaró competente para resolver la disputa en razón del acuerdo arbitral firmado por Ullrich con la UCI.

Un primer tema saliente respecto a la etapa de fondo, es que el Panel TAS tomó nota que las pruebas presentadas en el proceso no fueron obtenidas por un organismo antidopaje sino por la Guardia Civil española. ${ }^{61}$ Dado que el Art. 9 (ii) de las Reglas de la UCI le otorgan capacidad para revisar casos en los que se analicen muestras obtenidas por entidades que no sean organizaciones antidopaje, el Panel consideró que las Reglas de la UCI eran aplicables al caso.

Para la etapa de fondo, la defensa de Ullrich se fundamentó en aspectos que atacaban la legitimación activa de la UCI para presentar una apelación ante el TAS sobre la base de las Reglas de la UCI. Específicamente el atleta alegó que:

- La carta que la UCI envió a la FCS solicitando que se inicie el proceso disciplinario era ambigua y que no afirmaba que existiera una violación a reglas antidopaje lo cual violaba las Reglas de la UCI;

- Que con la carta de la UCI, la FCS debía convocarlo dentro de dos días y que la FCS no lo había hecho lo que violaba también las Reglas de la UCI; ${ }^{63}$

El Panel TAS determinó que la carta de la UCI era suficientemente clara respecto a las violaciones que se le imputaban al deportista. Respecto a la falta de citación, el Panel resolvió que no se le habia causado un perjuicio a Ullrich y que el deportista

61. Párrafo 26 del laudo definitivo.

62. Párrafo 32 a) del laudo definitivo.

63. Párrafo 32 b) del laudo definitivo, 
no podía alegar que no conocía del proceso, dado que incluso había sido despedido de su equipo a raíz de la Operación Puerto y la investigación de la UCI; adicionalmente el Panel se fundamentó en que su capacidad de revisar de novo lo actuado en primera instancia le permitía subsanar cualquier defecto procesal que se hubiera producido.

Ullrich alegó además que la UCI había cometido un error al plantear la apelación en contra del organismo olímpico suizo y no en contra de la FCS; según el ciclista, esta omisión violaba el Código Civil Suizo. El Panel TAS encontró que tal alegación carecía de mérito dado que las Reglas de la UCI eran claras respecto a que la apelación debía plantearse en contra del deportista de la "federación" responsable de la primera instancia y/o el organismo que actuó en su representación.

Adicionalmente Ullrich arguyó que la UCI no tenía capacidad para apelar de la decisión de primera instancia puesto que él había renunciado a su membrecía a la FCS lo que lo descartaba como un "tenedor de licencia" de acuerdo a las Reglas de la UCI. Sin embargo, nuevamente, el Panel TAS encontró que tal afirmación no tenía fundamento dado que las Reglas de la UCI consideran tenedores de licencia también a aquellos atletas que dejen de ser miembros durante la marcha de un proceso disciplinario.

Respecto a las pruebas presentadas durante el proceso, el Panel tomó en consideración que la evidencia demostraba que: 1) Jan Ullrich estuvo en Madrid múltiples veces en fechas que no tenían que ver con el calendario ciclístico; 2) que Ullrich pagó importantes sumas de dinero al principal acusado de la Operación Puerto (Dr. Fuentes); y 3) exámenes de ADN realizados a Ullrich demostraron que el perfil genético del ciclista empataba con las bolsas de sangre encontradas en poder del Dr. Fuentes. ${ }^{64}$

Por todo lo anterior, el Panel TAS encontró más allá de la cómodo satisfacción, que Jan Ullrich era culpable de violaciones a 
reglas antidopaje de acuerdo a las Reglas de la UCI. La sanción que se le aplicó al ciclista fue la descalificación de todos los resultados obtenidos desde el 1 mayo del 2005 y la prohibición de participar en eventos por dos años.

Un dato interesante de este caso es que la defensa de Ullrich prefirió no participar de la audiencia ante el panel TAS. Si es que existe algún caso particular en el que el acusado se benefició de no comparecer a ejercer su derecho de defensa, habrá que buscarlo en otro lado.

En su laudo, el panel TAS encontró "notable y sorprendente" que Ullrich nunca atacó la veracidad de las pruebas aportadas al proceso y que, más bien, su defensa se centró en asuntos procesales. ${ }^{65}$ Más allá del fracaso de su estrategia legal de buscar la absolución por aspectos meramente procesales, es tremendamente llamativo que Ullrich nunca disputó su culpabilidad.

\subsection{Lance Armstrong: el cambio radical de estrategia}

El estadounidense Lance Armstrong es el ciclista profesional más famoso y reconocido de esta generación. Este atleta se volvió una leyenda por ser un sobreviviente del cáncer y por ser el ciclista que más veces ha ganado el Tour de Francia (7 veces).

A los 25 años se le detectó un cáncer de testículo con metástasis a los pulmones y cerebro. Armstrong logró sobrevivir y su historia de superación, conjuntamente con sus logros deportivos, dieron lugar a la fundación Livestrong ${ }^{66}$ que ayuda a los enfermos en la lucha contra el cáncer y por la cual se encuentra a tantas personas por todo el mundo con pulseras amarillas de caucho.

Armstrong es el único ciclista profesional que ha "ganado" el Tour de Francia en 7 ocasiones (1999 a 2005). Durante toda su

65. Párrafo 66 del laudo delinitivo.

66. Pägina oficial de la Fundación Livestrong: http / www livestrong org 
vida se ha caracterizado por tener un carácter extremadamente fuerte y una competitividad intimidante.

Durante toda la carrera deportiva de Lance Armstrong, el corredor fue el blanco de acusaciones de dopaje. Durante 14 años de carrera se le practicaron cientos de controles antidopaje y oficialmente superó todos. El ciclista siempre se defendió de las imputaciones de dopaje atacando a sus acusadores a través de acciones legales y otras formas de intimidación.

En el 2005 el diario francés L'Equipe reportó que existían 6 muestras tomadas al ciclista durante el Tour de Francia de 1999 que, supuestamente, contenían EPO; sin embargo en el 2006 se desestimó esa acusación. ${ }^{67}$ En el 2010, Floyd Landis, ex compañero de equipo de Armstrong, dijo públicamente que él, Armstrong y otros miembros del mismo equipo habían usado sustancias prohibidas para mejorar su rendimiento. Desde ese momento en adelante, varios ex compañeros y personas relacionadas al ciclista comenzaron a contar su verdad. Armstrong se retiró definitivamente en febrero del 2011 manteniendo enérgicamente que todas las acusaciones en su contra eran únicamente una "cacería de brujas". ${ }^{68}$

En junio del 2012 la USADA inició una investigación oficial en contra de Lance Armstrong por dopaje y tráfico de drogas. En un último intento desesperado por esconder la verdad, el ciclista planteó una acción judicial ante un juez federal de Texas para intentar suspender el proceso ante la USADA. El juez federal a cargo desechó esta solicitud. En agosto de 2012 el ciclista anunció que no llevaría el caso a arbitraje de la $\mathrm{AAA}^{69}$ y el 22 de octubre la USADA le retiró todas las victorias del Tour de Francia y ordenó la devolución de todos los premios y dinero ganado durante toda su carrera, así como la suspensión de por vida. ${ }^{70}$ Armstrong

67. Lance Armstmng time line (USA Today): http://usatoday 30 usatoday com/sports/cycling/story/201208-23/lance-armstrong-timeline/57258518/1

68. Ibidem.

69. Lance Armstrmg Statcment on Declining Arhitration Itith the US Anti-Doping Agency (ABC News). http:/abcnews go.com/US/lance-armstrong-5tatement-declining-arbitration-us-antidoping/story?id 17069913 H.UNJFBaVVz_E 
tenía hasta el 27 de diciembre del 2012 para apelar ante el TAS y definitivamente no lo hizo. ${ }^{71}$

El caso que involucra a Armstrong y a muchos de sus compañeros de equipo ha sido llamado por la USADA como "el programa de dopaje más sofisticado, profesional y exitoso que el deporte jamás haya visto."72

¿Por qué Armstrong nunca apeló? Después de tantos años de lucha contra sus detractores, ¿por qué callar? A menos de que el propio ciclista cuente su verdad, cosa que hasta ahora no lo hace, no existirán respuestas claras a estas preguntas. Sin embargo sí cabe pensar que la evidencia con la que se terminó de sancionar al texano fue tan contundente que Armstrong sintió que sería fútil y hasta vergonzoso que un panel TAS conozca su caso. Pero al final de todo, la verdad debía surgir de alguna manera.

Ese final a la historia y leyenda de Lance Armstrong llegó en enero del 2013 con su admisión de que se dopó durante casi toda su carrera y que ganó sus siete Tours de Francia con la ayuda de sustancias prohibidas. ${ }^{73}$ El desprestigio de este atleta es total y existe la posibilidad de que varias empresas que lo auspiciaron y que varias personas a las que él atacó legalmente por hablar del dopaje de Armstrong ahora lo demanden por los daños causados. Más aun, la excelente labor de la Fundación Livestrong ahora se verá fuertemente afectada porque muchas personas dejarán de hacerle donaciones.

70. Lance Armstrong Timeline (NDTV Sports) http://sports,ndtv.com/othersports/cycling/item/1982/4-lance-armstrong-timeline

71. Lance Armstrong Will Not Appeal Lifetime Cycling Ban (Bicycling). http://www.bicycling.com/news/pro-cycling/lance-armstrong-will-not-appeal-lifetime-cycling-ban

72. Lance Armstrong s fall from grace: a complete timeline (NY Daily News) htlp://www.nydailynews.com/sports $/ \mathrm{i}$-team/cycle-deceit-timeline-fall-lance-armstrong-article1.1179861

73. Armstrong Admits Doping, and Says He Will Testifi (The New York Times) http://www.nytimes com/2013/01/15/sports/cycling/lance-armstrong-admits-doping-and-says-he-willtestify-against-cycling-oflicials.html?,$=0$ 


\section{CONCLUSiones}

Como se analizó, todos los ciclistas que han admitido ante el TAS haberse dopado pero que han tratado de justificar sus actos en errores de terceros, su involuntariedad, errores procesales y hasta en animales comestibles, fallaron en su intento de evitar una sanción. ¿Qué habría podido decir o hacer Lance Armstrong ante un panel TAS para preservar sus siete Tours de Francia? La respuesta es un contundente NADA y, al parecer, eso fue lo que entendieron el ciclista y sus abogados.

No es posible afirmar que los arbitrajes TAS en particular o el sistema de juzgamiento de violaciones a reglas antidopaje tengan un efecto inmediato para disminuir el uso de sustancias prohibidas en el ciclismo mundial. En cambio sí es posible afirmar que los paneles TAS han sido estrictos cuando los ciclistas han ingerido sustancias prohibidas.

Las estrategias planteadas por los atletas que aquí se han mencionado han sido variadas, creativas y tienen una importante similitud, todas fracasaron. Merece comentar que ningún ciclista trató de alegar frontal y demostradamente que no se hubiera dopado sino que, más bien, trataron de dar explicaciones de como las sustancias prohibidas llegaron a sus muestras sin su responsabilidad. La gran conclusión es que los ciclistas que han planteado una defensa de "sí me dopé pero soy inocente" no tienen éxito.

Otra conclusión es que las federaciones nacionales que han tratado de proteger a sus ciclistas dopados también fracasan rotundamente. En mi opinión es más reprochable la actitud de esas federaciones que la de los mismos ciclistas porque es el papel de las instituciones deportivas locales perseguir a los tramposos y porque proteger a esos mismos deportistas a la larga evidencia la corrupción que existe en ciertos órganos de justicia deportiva local. 
La tercera gran conclusión es que la próxima vez que un ciclista mundialmente famoso sea acusado de dopaje, deberá pensarlo mucho más que los arriba mencionados antes de derrochar tanta energía ante la prensa reclamando su inocencia, gastar importantísimas sumas de dinero en abogados, causar bochornos y perjuicios económicos a sus equipos y patrocinadores, pero sobre todo, acabar como mentirosos ante un mundo que en algún momento los admiró. 